\title{
Development of a self-scored persistent airflow obstruction screening questionnaire in a general Japanese population: the Hisayama study
}

This article was published in the following Dove Press journal:

International Journal of COPD

15 May 2017

Number of times this article has been viewed

\author{
Takuya Samukawa ${ }^{1, *}$ \\ Koichiro Matsumoto ${ }^{2, *}$ \\ Go Tsukuya' \\ Chihaya Koriyama ${ }^{3}$ \\ Satoru Fukuyama ${ }^{2}$ \\ Akifumi Uchida' \\ Keiko Mizuno' \\ Hironori Miyahara ${ }^{4}$ \\ Yutaka Kiyohara ${ }^{5}$ \\ Toshiharu Ninomiya ${ }^{6}$ \\ Hiromasa Inoue! \\ 'Department of Pulmonary Medicine, \\ Graduate School of Medical \\ and Dental Sciences, Kagoshima \\ University, Kagoshima, ${ }^{2}$ Research \\ Institute for Diseases of the \\ Chest, Graduate School of Medical \\ Sciences, Kyushu University, Fukuoka, \\ ${ }^{3}$ Department of Epidemiology and \\ Preventive Medicine, Graduate \\ School of Medical and Dental \\ Sciences, Kagoshima University, \\ ${ }^{4}$ Kagoshima Kouseiren Medical \\ Health Care Center, Kagoshima, \\ ${ }^{5}$ Hisayama Research Institute for \\ Lifestyle Diseases, ${ }^{6}$ Department of \\ Epidemiology and Public Health, \\ Graduate School of Medical Sciences, \\ Kyushu University, Fukuoka, Japan \\ *These authors contributed equally \\ to this work
}

Correspondence: Hiromasa Inoue Department of Pulmonary Medicine, Graduate School of Medical and Dental Sciences, Kagoshima University, 8-35-I Sakuragaoka, Kagoshima 890-8520, Japan Tel +8I 992756476

Fax +8I 992756482

Email inoue-pulm@umin.net
Background: The use of a simple screening questionnaire to detect persistent airflow obstruction (AO) in COPD may facilitate the early, accurate diagnosis of COPD in general practice settings.

Objective: This study developed an original persistent AO questionnaire for screening individuals with COPD in a general Japanese population.

Methods: A working group was established to generate initial draft questionnaire items about COPD. Eligible subjects aged 40 and older living in Japan were solicited to participate in a health checkup from 2014 to 2015 . In study I, 2,338 subjects who fully completed the initial draft questionnaire and who had valid spirometry measurements were statistically analyzed to determine the final questionnaire items as a COPD screening questionnaire (COPD-Q). Persistent $\mathrm{AO}$ was defined as a post-bronchodilator $\mathrm{FEV}_{1} / \mathrm{FVC}<0.70$. In study II, the working group analyzed the weighted scores for individual items and established a cutoff point for the COPD-Q based on the data of 2,066 subjects in the Hisayama study. Receiver operating characteristic (ROC) curves were used to examine the ability of the COPD-Q to discriminate between subjects with and without AO.

Results: The five-item COPD-Q was established based on 19 initial draft items in study I and the weighted scores of individual items. The overall area under the ROC curve for the COPD-Q was 0.796 (95\% confidence interval, $0.707-0.788$ ). A cutoff of 4 points resulted in a sensitivity of $71.0 \%$ and a specificity of $70.1 \%$. The positive predictive value was $10.8 \%$, and the negative predictive value was $97.9 \%$. The crude odds ratio of the COPD-Q for AO was 5.8.

Conclusion: The five-item COPD-Q is a useful questionnaire for diagnosing persistent AO in a general Japanese population and is expected to be an effective first-stage screening tool for detecting COPD.

Keywords: COPD screening, questionnaires, Japanese population, bronchodilator, pulmonary function tests, airflow obstruction

\section{Introduction}

COPD is a common condition that progresses into a life-threatening disease, and it has become the third leading cause of death in the world in 2012. ${ }^{1}$ Population-based studies have demonstrated overall COPD prevalence rates of between $5 \%$ and $15 \%$. $^{2-6}$

A large epidemiological study (the Nippon COPD Epidemiological [NICE] study) in Japan showed that the prevalence of airflow limitation was $10.9 \%$, and at least $8.6 \%$ of subjects were estimated to have COPD. ${ }^{7}$ COPD is commonly underdiagnosed and untreated, ${ }^{7,8}$ and many patients with early COPD are unaware of related symptoms. ${ }^{9,10}$ The importance of early COPD detection has been emphasized, ${ }^{11}$ since 
it is a preventable and treatable disease. However, in its advanced stages, there is a greater risk of developing other comorbidities, and mortality is increased.

The diagnosis of COPD is based on physiological pulmonary function tests using spirometry. Specifically, there must be persistent airflow obstruction (AO), defined by a post-bronchodilator forced expiratory volume in 1 second $\left(\mathrm{FEV}_{1}\right)$ /forced vital capacity $(\mathrm{FVC})$ ratio $<0.7,{ }^{12}$ or by agedependent values below the lower fifth percentile of this ratio (the lower limit of normal [LLN]). ${ }^{13,14}$ However, it is difficult to screen the general population for COPD using spirometry, since it is not available in many settings. There is no proven benefit of using spirometry to screen adults who have no smoking history and no respiratory symptoms. ${ }^{15}$

The use of simple COPD screening tools, such as the COPD Population Screener (COPD-PS) ${ }^{16}$ and the International Primary Care Airways Guidelines (IPAG) questionnaires, ${ }^{17}$ has been shown to be helpful for people at risk of developing COPD. These questionnaires reliably detect $\mathrm{AO}$ in the general population, and may facilitate the early, accurate diagnosis of COPD in general practice settings. ${ }^{18,19}$

However, the COPD-PS and IPAG questionnaires were originally developed and primarily validated in Western countries. We recently validated the COPD-PS and IPAG questionnaires in a general Japanese population and determined that the diagnostic cutoff point was different from the originally established cutoff points. ${ }^{20,21}$ One study found that the body mass index (BMI) item in the IPAG questionnaire was not statistically relevant in Japanese subjects who had early COPD identified by questionnaires. ${ }^{22}$ Thus, these questionnaires may inadequately assess COPD in the general Japanese population. Therefore, for the early detection of COPD in general Japanese populations, we sought to develop an original persistent $\mathrm{AO}$ questionnaire as a COPD screening questionnaire (COPD-Q).

\section{Methods}

\section{Overview}

To develop a self-scored persistent AO screening questionnaire, we performed the following two studies (Figure 1). In study I, a working group was assembled to generate initial draft items for the development of the COPD-Q. These items were administered to subjects at a comprehensive health examination $^{23}$ in Kagoshima Kouseiren Medical Health Care Center in Japan, and the final questionnaire items comprising the COPD-Q were determined statistically by comparing their responses to $\mathrm{FEV}_{1} / \mathrm{FVC}$ scores to identify individuals likely to have COPD.

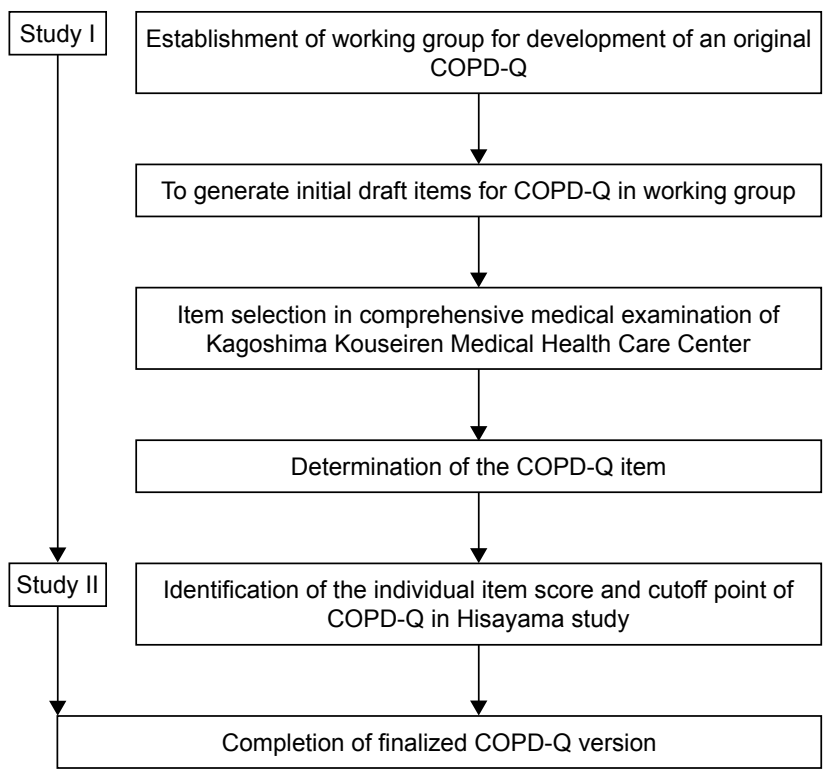

Figure I Study protocol.

Abbreviation: COPD-Q, COPD screening questionnaire.

In study II, the working group determined weighted scores for individual items and the cutoff point for the COPD-Q based on data derived from June 2015 to August 2015 from the Hisayama study, an ongoing, population-based epidemiologic study designed to investigate the morbidity, mortality, and risk factors of cardiovascular and smokingrelated diseases in the community of Hisayama, Japan.

\section{Working group and item generation}

The working group comprised three pulmonologists, one general physician, and one statistician, and met from August 2013 to April 2014 to generate initial draft items for the development of the COPD-Q. First, initial items were identified based on the following seven conceptual domains that were relevant to the detection of COPD and that could be easily evaluated by subjects: dyspnea, cough, phlegm, colds/bronchitis, wheezing, functional impact, and personal characteristics. The initial draft questionnaire consisted of 19 items (53 total questions) assessing the conceptual domains in terms of presence, frequency, duration, and/or quality.

\section{Study population}

In study I, Japanese participants aged 40-79 years who received comprehensive health examinations at Kagoshima Kouseiren Medical Health Care Center were enrolled in this study.

Study II was based on data from the Hisayama study, a town located in a suburban area adjacent to Fukuoka City, a large urban center on Kyushu Island in the southern part of Japan. 
The population of Hisayama is approximately 8,000 and has been stable for over 50 years. National census data show that the distributions of age and occupation in Hisayama have been almost identical to those across Japan since the 1960s.

\section{Study design}

The initial draft questionnaire was administered to the participants of study I. Of the 2,367 subjects who were enrolled from April 2014 to February 2015, three were excluded due to having asthma and 26 were excluded because data were missing in their records. The final analysis included data for 2,338 subjects with fully completed initial draft questionnaires and valid spirometry measurements. A random subsample of subjects $(22.9 \%)$ completed the survey again 2-4 weeks later to generate an estimate of test-retest reliability.

In study II, registered subjects aged 40 years and older were solicited to participate in a town-wide health checkup that included spirometry. Of the 2,598 subjects who were enrolled from June 2015 to August 2015, 532 were excluded for the following reasons: 342 were not between the ages of 40 and 79 years, 67 had physician-diagnosed asthma, 12 had a previous lung resection, two had poor study data, and 64 had records with missing data. Furthermore, 45 subjects who had pre-bronchodilator $\mathrm{FEV}_{1} / \mathrm{FVC}<0.70$ were not eligible for post-bronchodilator testing because of underlying heart disease or other reasons. The final analysis included data for 2,066 subjects who had fully completed the COPD-Q and had valid spirometry measurements.

All subjects underwent spirometry using a CHESTGRAPH HI-105 spirometer (Chest MI, Tokyo, Japan). The subjects performed at least three FVC maneuvers according to the recommended methods. The data were examined by two pulmonary physicians who visually inspected the flow-volume curves and excluded subjects with poor study data. The highest $\mathrm{FEV}_{1}$ and $\mathrm{FVC}$ values were used in the present study. The reference values for percent predicted $\mathrm{FEV}_{1}$ were based on Japanese criteria. Subjects with a prebronchodilator $\mathrm{FEV}_{1} / \mathrm{FVC}<0.70$ were required to undergo post-bronchodilator spirometry after 15-minute inhalation of salbutamol (GlaxoSmithKline, Tokyo, Japan) via a metered-dose inhaler with a spacer, according to the recommended procedure. Persistent AO was defined as a postbronchodilator $\mathrm{FEV}_{1} / \mathrm{FVC}<0.70$. The severity of subjects with persistent $\mathrm{AO}$ was categorized in accordance with the Global Initiative for Chronic Obstructive Lung Disease criteria (mild, $\mathrm{FEV}_{1} \geq 80 \%$ predicted; moderate, $\mathrm{FEV}_{1} 50 \%-80 \%$ predicted; severe, $\mathrm{FEV}_{1} 30 \%-50 \%$ predicted; very severe, $\mathrm{FEV}_{1}<30 \%$ predicted).
The study protocol was approved by the Institutional Review Board for Clinical Research of Kyushu University, by Kagoshima University, and by the Kagoshima Prefectural Federation of Agricultural Cooperatives for Health and Welfare. All subjects provided written informed consent prior to study participation.

\section{Statistical analysis}

The demographic characteristics of each study population and the questionnaire results were summarized with descriptive statistics. For subjects who used a bronchodilator, the post-bronchodilator $\mathrm{FEV}_{1} / \mathrm{FVC}$ values were utilized as the $\mathrm{FEV}_{1} / \mathrm{FVC}$ data. Each demographic characteristic was compared between groups using the Kruskal-Wallis test.

For study I, univariate/multivariate logistic regression models were used to compare questionnaire responses in the No-AO and AO groups, and to investigate initial draft items for the development of the COPD-Q. Test-retest reliability of the initial draft questionnaire was assessed with Pearson's correlations between scores at study entry and after 2-4 weeks of follow-up.

For study II, multivariate logistic regression analysis was performed to determine the weighted scores of each response to questions in the COPD-Q and to identify the COPD-Q cutoff point that would discriminate between subjects with and without persistent AO.

Sensitivity, specificity, and positive (PPV) and negative predictive value (NPV) were calculated. Receiver operating characteristic (ROC) curves were generated and area under the ROC curves (AUC) were determined to reflect the ability of the COPD-Q to discriminate between subjects with and without persistent AO graphically and quantitatively. Distribution of the number of subjects and COPD-Q scores, and their estimated probabilities of AO were evaluated.

These statistical analyses were performed using STATA Release 13 (StataCorp, College Station, TX, USA) and SAS Release 9.4 (SAS Institute Inc., Cary, NC, USA). Results were considered statistically significant when $P<0.05$.

\section{Results}

\section{Study I: subject characteristics}

Table 1 shows the baseline characteristics of the 2,338 subjects in study I, stratified by AO category following post-bronchodilator spirometry. The majority of subjects (95.8\%) showed an initial $\mathrm{FEV}_{1} / \mathrm{FVC} \geq 0.70$. Following postbronchodilator spirometry, $2.8 \%$ were found to have AO. Many AO subjects (89.2\%) were estimated as having mild or moderate COPD, while only $10.8 \%$ of AO subjects had 
Table I Baseline characteristics in study I

\begin{tabular}{|c|c|c|c|c|}
\hline \multirow[t]{3}{*}{ Characteristics } & \multicolumn{2}{|l|}{ No AO } & \multirow[t]{3}{*}{ AO } & \multirow[t]{3}{*}{$P$-value } \\
\hline & Pre-BD & Pre-BD & & \\
\hline & $F^{\prime} V_{1} / F V C \geq 0.70$ & FEV, IFVC $<0.70$ & & \\
\hline Subjects, n $(2,338)$ & 2,240 & 33 & 65 & \\
\hline Age (years), mean (SD) & $56.7(9.5)$ & $59.1(8.7)$ & $63.1(9.3)$ & $<0.001$ \\
\hline Male (\%) & 73.1 & 90.9 & 96.9 & \\
\hline Female $(\%)$ & 26.9 & 9.1 & 3.1 & \\
\hline BMI $\left(\mathrm{kg} / \mathrm{m}^{2}\right)$, mean $(\mathrm{SD})$ & $23.6(3.4)$ & $23.2(2.8)$ & $23.5(3.1)$ & 0.977 \\
\hline \multicolumn{5}{|l|}{ Brinkman index (\%) } \\
\hline Never smoker & 46.0 & 24.2 & 10.8 & \\
\hline $1-199$ & 10.6 & 9.1 & 4.6 & \\
\hline $200-399$ & 12.3 & 12.1 & 12.3 & \\
\hline $400-999$ & 26.4 & 45.5 & 47.7 & \\
\hline$>1,000$ & 4.7 & 9.1 & 24.6 & \\
\hline Mean (SD) & $266.2(364.1)$ & $419.6(393.4)$ & $654.3(425.0)$ & $<0.001$ \\
\hline Median (IQR) & $60(0-460)$ & $400(32-615)$ & $600(360-940)$ & \\
\hline \% FVC, mean (SD) & $104.4(14.5)$ & $106.6(13.2)$ & $91.3(20.8)$ & $<0.001$ \\
\hline Pre-BD FEV $(\%$ predicted), mean (SD) & $105.6(15.4)$ & $91.9(14.2)$ & $75.8(20.3)$ & $<0.001$ \\
\hline Post-BD FEV $(\%$ predicted), mean (SD) & NA & I03.I (13.0) & $82.0(19.2)$ & \\
\hline Pre-BD FEV/FVC (\%), mean (SD) & $81.6(5.0)$ & $67.7(2.1)$ & $62.7(6.4)$ & $<0.001$ \\
\hline Post-BD FEV,/FVC (\%), mean (SD) & NA & $73.5(2.2)$ & $64.1(6.1)$ & \\
\hline Reversibility (\%) & NA & 45.5 & 24.6 & \\
\hline \multicolumn{5}{|l|}{ COPD stage (\%) } \\
\hline I (mild) & NA & NA & 44.6 & \\
\hline II (moderate) & NA & NA & 44.6 & \\
\hline III (severe) & NA & NA & 9.2 & \\
\hline IV (very severe) & NA & NA & 1.5 & \\
\hline
\end{tabular}

Notes: No AO: post-bronchodilator FEV,/FVC $\geq 0.70$; AO: post-bronchodilator FEV,/FVC <0.7.

Abbreviations: AO, airflow obstruction; BD, bronchodilator; $\mathrm{FEV}$, forced expiratory volume in I second; FVC, forced vital capacity; SD, standard deviation; BMI, body mass index; IQR, interquartile range; NA, not applicable.

severe or very severe COPD. AO subjects were older, predominantly male, had a higher number of pack-years smoked, and were more likely to be former or current smokers (Table 1).

\section{Questionnaire item selection}

The 19 initial draft items were administered to all 2,338 subjects. Less than $4.0 \%$ of total item-level data were missing. Scale reliability was confirmed with the test-retest reliability method, with analysis of 535 subjects $(22.9 \%)$ who completed the study survey at entry and at 2-4 weeks of follow-up. In this population, the test-retest Pearson's correlation coefficient was $0.946(P<0.001)$.

Initial univariate logistic regression analysis was performed on the initial draft items (Tables S1 and 2). As stated above, items were grouped into the following conceptual domains: dyspnea, cough, phlegm, wheezing, functional impact, and personal characteristics. A combination of one item based on two conceptual domains, namely cough and phlegm, and one based on dyspnea on exertion, showed a significant ability to discriminate between subjects with and without AO. The final version of the COPD-Q consisted of the five questions $(\mathrm{Q})$ that demonstrated the greatest discriminatory capacity: How old are you? (Q1); How often do you cough up phlegm when you are not sick? (Q2); Are you prone to being out of breath when running or carrying a heavy load, compared to people of your own age group? (Q3); In the past year, have you ever had wheezing or whistling when breathing while running or carrying a heavy load? (Q4); How many cigarettes do you smoke? (Brinkman index: the number of cigarettes $\times$ the number of years) (Q5). Table 2 presents the results of univariate logistic regression analysis of these five questions (COPD-Q) as a screening questionnaire for persistent AO estimated to have COPD. Table 3 presents the results of odds ratios, and the corresponding $95 \%$ confidence intervals [CIs] were obtained by multivariable logistic regression analysis using age and cigarette consumption as covariates.

\section{Study II: subject characteristics}

Table 4 shows the baseline characteristics of the 2,069 subjects, based on data from the Hisayama study, stratified 
Table 2 Results of univariate logistic regression analyses

\begin{tabular}{|c|c|c|c|}
\hline \multirow[t]{2}{*}{ Item } & \multicolumn{3}{|c|}{ Analytic subjects $(\mathrm{N}=\mathbf{2 , 3 3 8})$} \\
\hline & OR & $95 \% \mathrm{Cl}$ & $P$-value for trend \\
\hline \multicolumn{4}{|c|}{ QI How old are you? (years) } \\
\hline $40-49$ & 1.0 & Reference & $<0.001$ \\
\hline $50-59$ & 1.4 & $0.6-3.4$ & \\
\hline $60-69$ & 3.7 & $1.6-8.6$ & \\
\hline$\geq 70$ & 5.1 & $2.1-13$ & \\
\hline \multicolumn{4}{|c|}{ Q2 How often do you cough up phlegm when you are not sick? } \\
\hline Almost never & 1.0 & Reference & $<0.001$ \\
\hline Rarely & 1.6 & $0.8-4.4$ & \\
\hline Sometimes & 2.3 & 1.2-4.4 & \\
\hline Frequently & 4.6 & $1.7-13$ & \\
\hline Very frequently & 3.1 & $0.4-24$ & \\
\hline \multirow{2}{*}{\multicolumn{4}{|c|}{$\begin{array}{l}\text { Q3 Are you prone to being out of breath when running or carrying a } \\
\text { heavy load, compared to people of your own age group? }\end{array}$}} \\
\hline & & & \\
\hline No & 1.0 & Reference & \\
\hline Yes & 2.2 & $1.3-3.6$ & \\
\hline \multirow{2}{*}{\multicolumn{4}{|c|}{$\begin{array}{l}\text { Q4 In the past year, have you ever had wheezing or whistling when } \\
\text { breathing while running or carrying a heavy load? }\end{array}$}} \\
\hline & & & \\
\hline Almost never & 1.0 & Reference & $<0.001$ \\
\hline Rarely & 3.7 & $2.0-6.8$ & \\
\hline Sometimes & 3.7 & I.8-7.4 & \\
\hline Frequently & 4.9 & $1.8-13$ & \\
\hline Very frequently & 2.9 & $0.4-23$ & \\
\hline \multicolumn{4}{|c|}{ Q5 How many cigarettes do you smoke? (Brinkman index) } \\
\hline Never smoked & 1.0 & Reference & $<0.00 \mathrm{I}$ \\
\hline $1-299$ & 1.7 & $0.6-5.3$ & \\
\hline $300-499$ & 3.3 & I.2-8.7 & \\
\hline $500-999$ & 8.4 & $3.8-19$ & \\
\hline$\geq 1,000$ & 19 & $8.0-46$ & \\
\hline
\end{tabular}

Notes: Brinkman index: number of cigarettes smoked per day $\times$ number of years of the habit. $P$-value for trend was obtained by logistic regression models using each variable as a continuous variable.

Abbreviations: $\mathrm{OR}$, odds ratio; $\mathrm{Cl}$, confidence interval.

by airflow limitation category following post-bronchodilator spirometry. The majority of subjects (95.2\%) showed an initial $\mathrm{FEV}_{1} / \mathrm{FVC} \geq 0.70$. Following post-bronchodilator spirometry, $4.8 \%$ were found to have AO. Almost all AO subjects $(93.0 \%)$ were classified as having mild or moderate COPD, while only $7.0 \%$ had severe or very severe COPD. As in study I, AO subjects were older, predominantly male, had a higher number of pack-years smoked, and were more likely to be former or current smokers (Table 4).

\section{Item-weighted scoring and cutoff point}

The COPD-Q was administered to all 2,069 subjects in Hisayama, and several versions of weighted scores were assessed to produce the best results for discriminating between patients with and without AO. We ultimately derived weighted scores for the five COPD-Q questions according to individual coefficients of the multivariate logistic regression analysis (Table 5). Responses to each question were assigned weighted
Table 3 Results of multivariable logistic regression analyses

\begin{tabular}{lcll}
\hline Item & \multicolumn{3}{c}{ Analytic subjects $(\mathbf{N}=\mathbf{2 , 3 3 8})$} \\
\cline { 2 - 4 } OR & $\mathbf{9 5 \%} \mathbf{~ C l}$ & P-value for trend \\
\hline QI How old are you? & (years) & & \\
$40-49$ & 1.0 & Reference & $<0.00$ I \\
$50-59$ & 1.1 & $0.4-2.8$ & \\
$60-69$ & 2.5 & $1.0-5.8$ & \\
$\geq 70$ & 4.3 & $1.7-11$ & \\
Q2 How often do you cough up phlegm when you are not sick? \\
Almost never & I.0 & Reference & $<0.00$ I \\
Rarely & 1.5 & $0.8-2.9$ & \\
Sometimes & 2.1 & $1.1-4.0$ & \\
Frequently & 2.7 & $0.9-7.7$ & \\
Very frequently & 2.6 & $0.3-21$
\end{tabular}

Q3 Are you prone to being out of breath when running or carrying a heavy load, compared to people of your own age group?

$\begin{array}{lll}\text { No } & 1.0 & \text { Reference } \\ \text { Yes } & 1.9 & 1.1-3.2\end{array}$

Q4 In the past year, have you ever had wheezing or whistling when breathing while running or carrying a heavy load?

$\begin{array}{llll}\text { Almost never } & 1.0 & \text { Reference } & <0.00 \mathrm{I} \\ \text { Rarely } & 3.5 & 1.9-6.6 & \\ \text { Sometimes } & 3.1 & 1.5-6.4 & \\ \text { Frequently } & 4.3 & 1.5-12 & \\ \text { Very frequently } & 2.9 & 0.4-24 & \\ \text { Q5 How many cigarettes do you smoke? (Brinkman index) } \\ \text { Never smoked } & 1.0 & \text { Reference } & <0.00 \mathrm{I} \\ \text { I-299 } & 2.1 & 0.7-6.6 & \\ 300-499 & 3.9 & 1.5-11 & \\ 500-999 & 9.3 & 4.2-21 & \\ \geq 1,000 & 17 & 7.1-41 & \end{array}$

Notes: Brinkman index: number of cigarettes smoked per day $\times$ number of years of the habit. ORs and corresponding $95 \% \mathrm{Cls}$ were obtained by multivariable logistic regression analysis using age and cigarette consumption as covariates.

Abbreviations: $\mathrm{OR}$, odds ratio; $\mathrm{Cl}$, confidence interval.

scores (specifically, depending on the question, 0 or 1 ; 0,1 , or 2 ; or $0,1,2$, or 3 ) based on the relative contribution of the response to identifying $\mathrm{AO}$, and response values were summed across the items to produce a scale score ranging from 0 to 10 . Three of the five COPD-Q assessed COPD-related symptoms, namely coughing up phlegm (Q2; 5-point scale), breathlessness on exertion (Q3; 2-point scale), and wheezing on exertion (Q4; 5-point scale). One evaluated subject age (Q1; four categories), and the last assessed smoking history (Q5; 4-point scale) (Figures 2 and S1). An ROC curve was generated to evaluate the ability of the final version of the COPD-Q to discriminate subjects without AO from those with AO in study II (Hisayama study) (Figure 3). The overall AUC for the continuous COPD-Q score for discriminating AO from No AO was 0.796 (95\% CI, 0.750-0.841). The appropriateness of various cutoff points of the COPD-Q was then evaluated (Table 6). A cutoff of 4 points showed a sensitivity of $71.0 \%$ and a specificity of $70.1 \%$. The PPV was $10.8 \%$, 
Table 4 Baseline characteristics in study II

\begin{tabular}{|c|c|c|c|c|}
\hline \multirow[t]{3}{*}{ Characteristics } & \multicolumn{2}{|l|}{ No AO } & \multirow[t]{3}{*}{ AO } & \multirow[t]{3}{*}{$P$-value } \\
\hline & \multirow{2}{*}{$\frac{\text { Pre-BD }}{\text { FEV }_{\text {I }} \text { FVC } \geq 0.70}$} & \multirow{2}{*}{$\frac{\text { Pre-BD }}{\text { FEV }_{\text {I }} \text { FVC }<0.70}$} & & \\
\hline & & & & \\
\hline Subjects, n $(2,066)$ & 1,903 & 63 & 100 & \\
\hline Age (years), mean (SD) & $61.1(10.7)$ & $67.9(8.7)$ & $68.0(8.1)$ & $<0.001$ \\
\hline Male (\%) & 41.9 & 39.7 & 71.0 & \\
\hline Female (\%) & 58.1 & 60.3 & 29.0 & \\
\hline BMI $\left(k g / m^{2}\right)$, mean $(S D)$ & $23.2(10.7)$ & $22.8(3.3)$ & $22.6(3.0)$ & 0.256 \\
\hline \multicolumn{5}{|l|}{ Brinkman index (\%), mean (SD) } \\
\hline Never smoker & 57.8 & 65.1 & 26.0 & \\
\hline $1-199$ & 8.4 & 6.3 & 6.0 & \\
\hline $200-399$ & 8.9 & 3.2 & 7.0 & \\
\hline 400-999 & 19.6 & 22.2 & 30.0 & \\
\hline$>1,000$ & 5.3 & 3.2 & 31.0 & \\
\hline Mean (SD) & $227.5(374.0)$ & $206.0(338.6)$ & $630.5(546.9)$ & $<0.001$ \\
\hline Median (IQR) & $0(0-390)$ & $0(0-360)$ & $600(0-1,000)$ & \\
\hline \% FVC, mean (SD) & $100.4(13.3)$ & $102.6(14.3)$ & $92.6(15.9)$ & $<0.001$ \\
\hline Pre-BD FEV (\% predicted), mean (SD) & $95.8(13.7)$ & $87.1(13.2)$ & $73.5(15.3)$ & $<0.001$ \\
\hline Post-BD FEV $(\%$ predicted), mean (SD) & NA & $93.3(13.3)$ & $77.1(16.4)$ & \\
\hline Pre-BD FEV,/FVC (\%), mean (SD) & $78.1(4.8)$ & $67.9(1.8)$ & $63.6(4.8)$ & $<0.001$ \\
\hline Post-BD FEV/FVC (\%), mean (SD) & NA & $72.3(2.4)$ & $64.7(5.1)$ & \\
\hline Reversibility (\%) & NA & 12.7 & 14.0 & \\
\hline \multicolumn{5}{|l|}{ COPD stage (\%) } \\
\hline I (mild) & NA & NA & 34.0 & \\
\hline II (moderate) & NA & NA & 59.0 & \\
\hline III (severe) & NA & NA & 7.0 & \\
\hline IV (very severe) & NA & NA & 0.0 & \\
\hline
\end{tabular}

Notes: No AO: post-bronchodilator $\mathrm{FEV}_{1} / \mathrm{FVC} \geq 0.70$; AO: post-bronchodilator $\mathrm{FEV}_{\mathrm{I}} / \mathrm{FVC}<0.7$.

Abbreviations: $A O$, airflow obstruction; $B D$, bronchodilator; $\mathrm{FEV}_{1}$, forced expiratory volume in I second; FVC, forced vital capacity; SD, standard deviation; BMI, body mass index; IQR, interquartile range; NA, not applicable.

Table 5 Weighted scores based on coefficients in multivariate logistic regression analyses of COPD-Q

\begin{tabular}{|c|c|c|c|c|c|}
\hline Question & Point scale & Coefficient & Standard error & $P$-value & Weighted score \\
\hline \multirow[t]{4}{*}{ QI } & $40-49$ years old & - & - & - & 0 \\
\hline & 50-59 years old & 0.589 & 0.619 & 0.342 & I \\
\hline & 60-69 years old & 1.613 & $0.54 I$ & 0.003 & 2 \\
\hline & Over 70 years old & 2.068 & 0.539 & $<0.001$ & 3 \\
\hline \multirow[t]{5}{*}{ Q2 } & Almost never & - & - & - & 0 \\
\hline & Rarely & -0.210 & $0.34 I$ & 0.537 & 0 \\
\hline & Sometimes & 0.672 & 0.276 & 0.015 & I \\
\hline & Frequently & 0.594 & 0.582 & 0.307 & 1 \\
\hline & Very frequently & 0.373 & 0.838 & 0.656 & I \\
\hline \multirow[t]{2}{*}{ Q3 } & No & - & - & - & 0 \\
\hline & Yes & 0.506 & 0.262 & 0.053 & I \\
\hline \multirow[t]{5}{*}{ Q4 } & Almost never & - & - & - & 0 \\
\hline & Rarely & 0.383 & 0.324 & 0.238 & 0 \\
\hline & Sometimes & 0.333 & 0.356 & 0.351 & 0 \\
\hline & Frequently & 0.937 & 0.597 & 0.117 & I \\
\hline & Very frequently & 1.743 & 0.746 & 0.019 & 2 \\
\hline \multirow[t]{5}{*}{ Q5 } & No smoking & - & - & - & 0 \\
\hline & $1-199$ & 0.627 & $0.47 \mid$ & 0.183 & I \\
\hline & $200-399$ & 0.754 & 0.457 & 0.099 & I \\
\hline & $400-999$ & 1.116 & 0.288 & $<0.001$ & 2 \\
\hline & Over 1,000 & 2.089 & 0.306 & $<0.001$ & 3 \\
\hline
\end{tabular}

Notes: Q1, How old are you?; Q2, How often do you cough up phlegm when you are not sick?; Q3, Are you prone to being out of breath when running or carrying a heavy load, compared to people of your own age group?; Q4, In the past year, have you ever had wheezing or whistling when breathing while running or carrying a heavy load?; Q5, How many cigarettes do you smoke? (Brinkman index: number of cigarettes smoked per day $\times$ years smoked).

Abbreviation: COPD-Q, COPD screening questionnaire. 


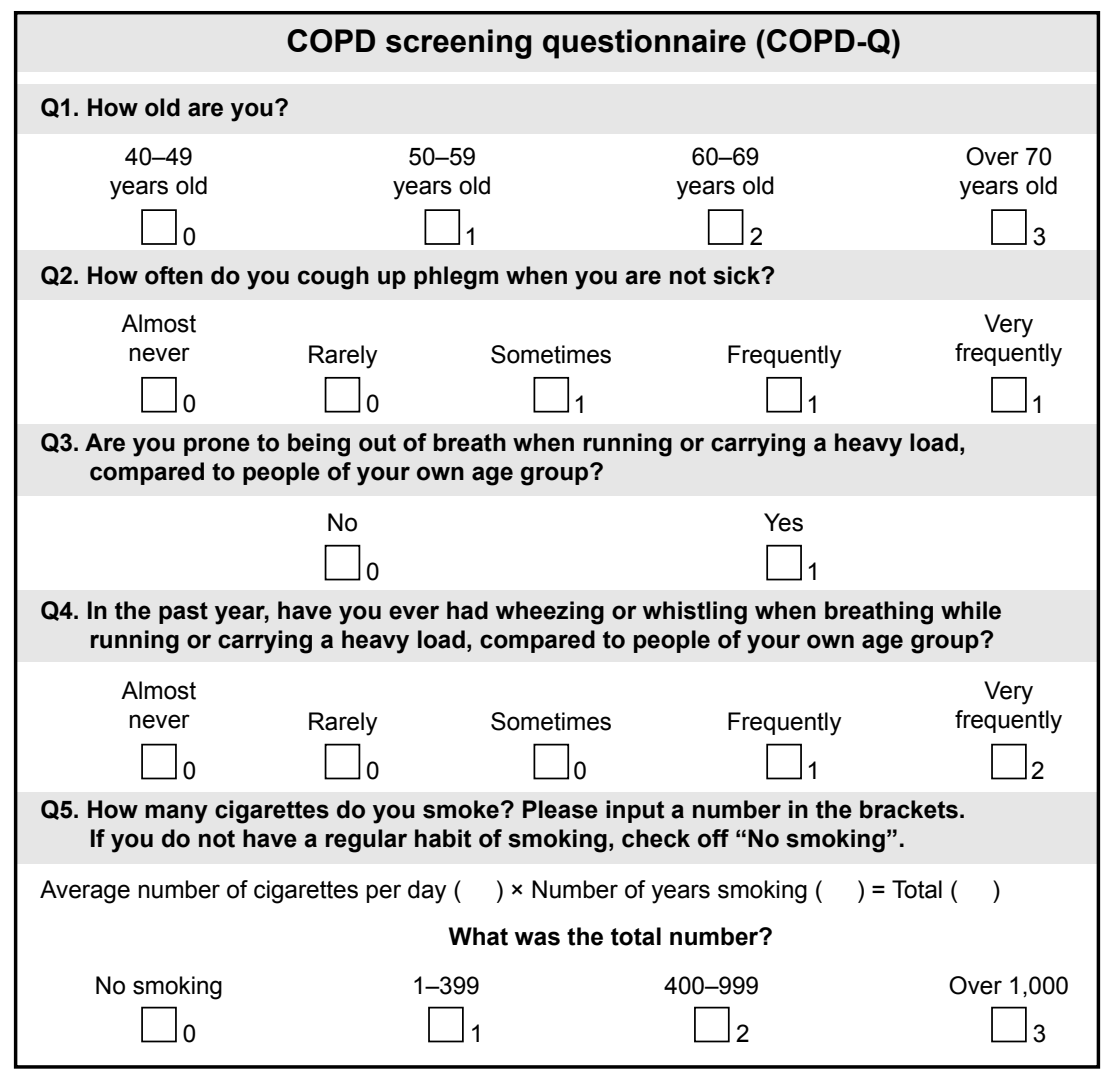

Figure 2 A self-scored COPD screening questionnaire.

the NPV was $97.9 \%$, and the crude odds ratio (OR) of the COPD-Q for AO was 5.8. The relationship between COPD-Q score of $\mathrm{AO}$ subjects ranging from 0 to 10 and estimated probability is shown in Figure 4. The estimated probabilities for AO tended to increase with COPD-Q scores.

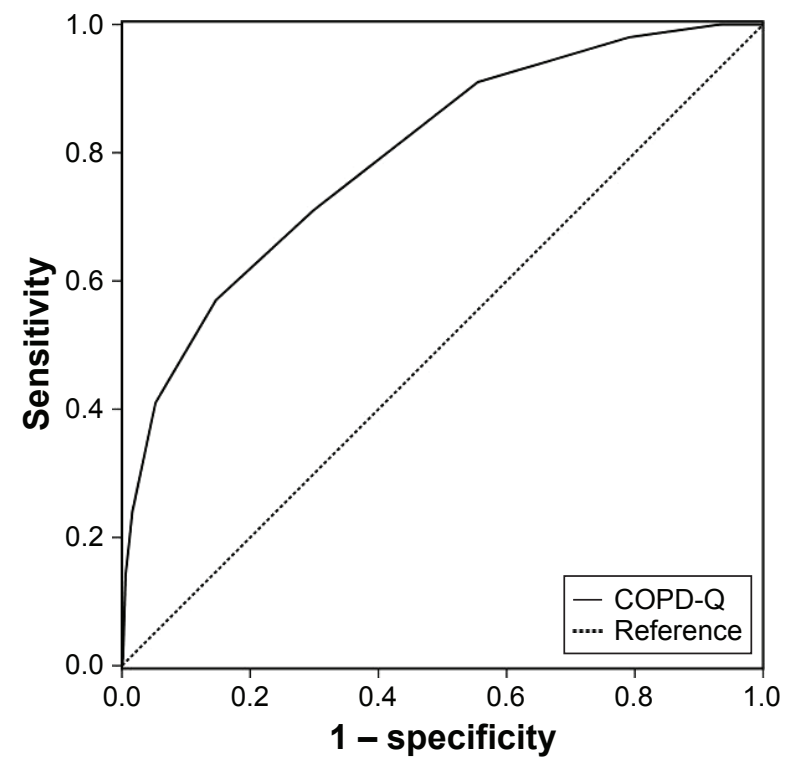

Figure 3 Receiver operating characteristic curve of the COPD-Q for discriminating between subjects with and without $A O$.

Abbreviations: COPD-Q, COPD screening questionnaire; $A O$, airflow obstruction.

\section{Discussion}

The five-item, self-scored COPD-Q is a simple and reliable Japanese-language questionnaire that was developed to screen for persistent AO estimated to have COPD in a general Japanese population.

In study I, the working group generated initial draft items derived from 19 items comprising 53 total questions based on seven conceptual domains. Ten items demonstrated a particularly strong relationship to COPD. Although BMI was assessed by an item in the IPAG questionnaire, it was not a significant predictive factor for AO in this study (Tables 1 and 4), a result that is consistent with a previous report. ${ }^{22}$ An obvious problem concerning BMI is that the cutoff values of BMI of 25.4 and $29.7 \mathrm{~kg} / \mathrm{m}^{2}$ in the IPAG questionnaire are well above the average BMI of Japanese subjects, and even above the Japanese criteria for obesity of $25.0 \mathrm{~kg} / \mathrm{m}^{2}$. Thus, there are reports stating that modified cutoff values for BMI should be used for determining the discriminatory power of the IPAG questionnaire for the Japanese population. ${ }^{22,24}$ However, regarding $B M I$ in the present study, there were no significant differences between subjects with $\mathrm{AO}$ and those without $\mathrm{AO}$ in study I (Table 1) or study II (Table 4), and as a result, we excluded BMI as an item in the COPD-Q. In addition, some reports have shown that the association between BMI and 
Table 6 Various cutoff points for the COPD-Q

\begin{tabular}{llllllll}
\hline $\begin{array}{l}\text { Cutoff } \\
\text { point }\end{array}$ & OR & Sensitivity (\%) & Specificity (\%) & $\begin{array}{l}\text { Positive predictive } \\
\text { value (\%) }\end{array}$ & $\begin{array}{l}\text { Negative predictive } \\
\text { value (\%) }\end{array}$ & $\begin{array}{l}\text { Percent correctly } \\
\text { classified }\end{array}$ & \begin{tabular}{l} 
AUC (\%) \\
\hline 2
\end{tabular} \\
\hline 13.0 & 98.0 & 20.9 & 5.9 & 99.5 & 24.6 & 59.5 \\
3 & 8.1 & 91.0 & 44.5 & 7.7 & 99.0 & 46.8 & 70.2 \\
4 & 5.8 & 71.0 & 70.1 & 10.8 & 97.9 & 84.0 & 70.6 \\
5 & 7.2 & 57.0 & 85.4 & 16.5 & 97.5 & 92.2 & 71.2 \\
6 & 12.6 & 41.0 & 94.8 & 28.5 & 96.9 & 94.8 & 67.6 \\
7 & 19.1 & 24.0 & 98.4 & 42.9 & 96.2 & 61.2 \\
\hline
\end{tabular}

Abbreviations: COPD-Q, COPD screening questionnaire; OR, odds ratio; AUC, area under the receiver operating characteristic curve.

mortality was especially significant in severe COPD and differed according to the severity of $\mathrm{AO} ;{ }^{25,26}$ however, subjects of AO in the present study ( $89.2 \%$ in study I and $93.0 \%$ in study II) were in Global Initiative for Chronic Obstructive Lung Disease stage I and II. The BMI in subjects with early-detected COPD may not be a significant item in Japanese population.

Univariate logistic regression analyses were used to identify five items that predicted COPD (Table 2). Coughing, as identified by a general clinician in relation to COPD, did not by itself distinguish between subjects with $\mathrm{AO}$ and those without AO. The combination of coughing and phlegm production (addressed by Q2) showed significant discriminatory ability, similar to that of dyspnea on exertion (addressed by Q3), and the ORs of both Q2 and Q3 were significant in a multivariate logistic regression analysis (Table 3).

Study I has several limitations regarding data interpretation. The prevalence of persistent AO estimated to have COPD was $2.8 \%$, which is very low compared with a previous report. ${ }^{7}$ The study population comprised individuals who voluntarily agreed to participate in an annual comprehensive health examination program that is conducted in Japan to detect potential health risks at an early stage. ${ }^{23}$ This survey population may be healthier or more health conscious than the general Japanese population, which

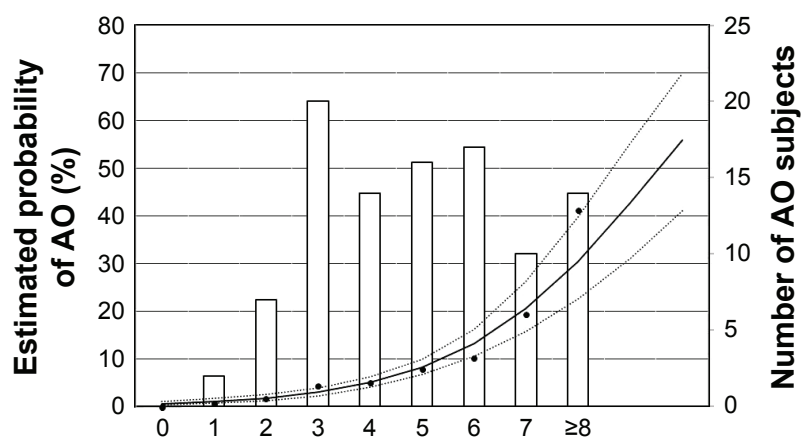

Figure 4 The relationship between COPD-Q score and estimated probability of $A O$ (\%). Bars represent the number of $A O$ subjects. Black circles: observed $A O$ (\%), curve: estimated $\mathrm{AO}(\%)$, dotted curves: $95 \% \mathrm{Cl}$, and horizontal axis: COPD-Q scores. Abbreviations: COPD-Q, COPD screening questionnaire; $A O$, airflow obstruction; $\mathrm{Cl}$, confidence interval. would affect the prevalence of persistent AO estimated to have COPD in study I. Therefore, we analyzed the weighted scores for individual items and established a cutoff point for the COPD-Q based on the data from the Hisayama study (study II). It is necessary in the future to confirm the performance of the COPD-Q in other validation cohorts.

In study II, the five items on the COPD-Q were scored as $0,1,2$, or 3 based on coefficients of multivariate logistic regression analysis for identifying $\mathrm{AO}$, with a summed total score ranging from 0 to 10 (Figure 2). To evaluate the contribution of smoking status, we used the Brinkman index and derived weighted scores based on coefficients of multivariate logistic regression analysis for predicting COPD. The COPD-PS ${ }^{16}$ used the question "Have you smoked at least 100 cigarettes in your ENTIRE LIFE", and a "Yes" response was assigned a value of 2. Conversely, in the present study, the responses to the smoking status item were assigned values of $0,1,2$, or 3, because a total Brinkman index value over 1,000 was most useful for distinguishing COPD (Table 5).

The overall AUC for the continuous COPD-Q score was 0.796 (95\% CI, 0.750-0.841) (Figure 3). In a previous study, we administered the COPD-PS and IPAG questionnaires to a general Japanese population (Hisayama study), ${ }^{21}$ and found that the overall AUC for the COPD-PS was 0.747 (95\% CI, 0.707-0.788) and 0.775 (95\% CI, 0.735-0.816) for the IPAG questionnaire. In the present study with almost the same population, the COPD-Q showed a large AUC for distinguishing subjects with $\mathrm{AO}$ from those without $\mathrm{AO}$ compared to the COPD-PS and IPAG questionnaire.

The PPV of $10.8 \%$ with a COPD-Q cutoff point of 4 is lower than the PPVs obtained using the COPD-PS and IPAG questionnaires in our previous study. ${ }^{21}$ However, PPV and NPV vary with disease prevalence, with PPV decreasing with lower disease prevalence. The NICE study estimated that the COPD prevalence in Japan ranged from 8.6\% to $10.9 \% .^{7}$ In residents aged 40 years or older from Hisayama, Matsumoto et al estimated that the combined prevalence of COPD and a COPD phenotype with variable airflow limitation was $9.3 \%{ }^{27}$ 
However, the prevalence of confirmed persistent $\mathrm{AO}$ in the present study was $4.8 \%$ (Table 3 ) in residents from Hisayama aged 40-79 years. The following reasons may account for the underestimated persistent AO prevalence in study II. First, 342 subjects were excluded from the present study because they were not between 40 and 79 years old, and since the prevalence of COPD increases with older age, this age restriction may have affected the prevalence of AO. The prevalence of AO was previously found to be $19 \%$ in individuals in Hisayama between the ages of 80 and 89 years. ${ }^{27}$ The second potential reason for the underestimated persistent AO prevalence is that 67 subjects with physician-diagnosed asthma were excluded; however, these subjects may have had a COPD phenotype with variable $\mathrm{AO}$, which exhibits features of both asthma and COPD. ${ }^{28-30}$ The third possible explanation is that the 45 subjects with pre-bronchodilator $\mathrm{FEV}_{1} / \mathrm{FVC}<0.7$ were ineligible for post-bronchodilator testing and were excluded from the present study, and this group may have included subjects with persistent AO.

Another limitation of this study was that persistent $\mathrm{AO}$ estimated to have COPD was defined as a post-bronchodilator $\mathrm{FEV}_{1} / \mathrm{FVC}<0.7$ without using an $\mathrm{LLN}$, though previous studies demonstrated the successful use of an LLN for defining $\mathrm{AO}$ in Japanese populations. ${ }^{31,32}$ Application of an LLN value for determining the existence of COPD may prevent overdiagnosis in elderly subjects and underdiagnosis in young subjects. ${ }^{33}$

Despite these limitations, the COPD-Q developed in the present study was found to be a simple and useful screening questionnaire for persistent $\mathrm{AO}$ in a general Japanese population.

\section{Conclusion}

The COPD-Q is a five-item screening questionnaire for persistent AO. Although validation studies are necessary to confirm the performance of the COPD-Q in other cohorts, the COD-Q can be evaluated for its utility as a first-stage screening tool for detecting COPD in the general Japanese population.

\section{Acknowledgments}

This research was supported by a Grant-in Aid from Japan Society for the Promotion of Science (JSPS) and from Japan Agency for Medical Research and development, AMED. The authors thank Satoko Shimoota, Daichi Hamasaki, Akihiro Kakoi, Tadahiko Amiya, Manami Iwamoto, and Machiko Higo for their assistance in data collection. The Hisayama Pulmonary Physiology Study Group included
Satoru Fukuyama, Koichiro Matsumoto, Takako Nakano, Atsushi Moriwaki, Yuko Matsunaga, Keiko Kan-o, Naotaka Noda, Yukari Tajiri-Asai, Hiroko Hirai, Yumiko Ishii, Saaka Hamano, Ken Tonai, Nanae Seki, Ayako Hashizume, Makiko Kogo, Misae Awane, and Yoichi Nakanishi from Research Institute for Diseases of the Chest, Graduate School of Medical Sciences, Kyushu University, Fukuoka, Japan; Go Tsukuya, Takuya Samukawa, and Hiromasa Inoue from Department of Pulmonary Medicine, Graduate School of Medical and Dental Sciences, Kagoshima University, Kagoshima, Japan; Makoto Yoshida, Masashi Komori, and Yasuko Kaneko from Section of Pulmonary Medicine, Fukuoka National Hospital, Fukuoka, Japan; Shohei Takata and Mikiko Matsuo-Matsumura from Division of Respiratory Medicine, National Fukuoka-Higashi Medical Center, Fukuoka, Japan; Hiroshi Koto from Department of Respiratory Medicine, Kyushu Central Hospital, Fukuoka, Japan.

\section{Author contributions}

All authors contributed toward data acquisition, data analysis, and drafting and critically revising the paper and agree to be accountable for all aspects of the work.

\section{Disclosure}

The authors report no conflicts of interest in this work.

\section{References}

1. World Health Organization. World health statistics 2012. Available from: www.who.int/gho/publications/world_health_statistics/2012. Accessed December 2, 2016.

2. Menezes AM, Perez-Padilla R, Jardim JR, et al; PLATINO Team. Chronic obstructive pulmonary disease in five Latin American cities (the PLATINO study): a prevalence study. Lancet. 2005;366(9500):1875-1881.

3. Buist AS, McBurnie MA, Vollmer WM, et al; BOLD Collaborative Research Group. International variation in the prevalence of COPD (the BOLD Study): a population-based prevalence study. Lancet. 2007; 370(9589):741-750.

4. Soriano JB, Ancochea J, Miravitlles M, et al. Recent trends in COPD prevalence in Spain: a repeated cross-sectional survey 1997-2007. Eur Respir J. 2010;36(4):758-765.

5. Soriano JB, Rodriguez-Roisin R. Chronic obstructive pulmonary disease overview: epidemiology, risk factors, and clinical presentation. Proc Am Thorac Soc. 2011;8(4):363-367.

6. Kourlaba G, Hillas G, Vassilakopoulos T, Maniadakis N. The disease burden of chronic obstructive pulmonary disease in Greece. Int J Chron Obstruct Pulmon Dis. 2016;11:2179-2189.

7. Fukuchi $Y$, Nishimura M, Ichinose M, et al. COPD in Japan: the Nippon COPD Epidemiology study. Respirology. 2004;9(4):458-465.

8. Schermer TR, Jacobs JE, Chavannes NH, et al. Validity of spirometric testing in a general practice population of patients with chronic obstructive pulmonary disease (COPD). Thorax. 2003;58(10):861-866.

9. Calverley PM, Nordyke RJ, Halbert RJ, Isonaka S, Nonikov D. Development of a population-based screening questionnaire for COPD. COPD 2005;2(2):225-232.

10. Petty TL. The worldwide epidemiology of chronic obstructive pulmonary disease. Curr Opin Pulm Med. 1996;2(2):84-89. 
11. Rabe KF, Hurd S, Anzueto A, et al; Global Initiative for Chronic Obstructive Lung Disease. Global strategy for the diagnosis, management, and prevention of chronic obstructive pulmonary disease: GOLD executive summary. Am J Respir Crit Care Med. 2007;176(6):532-555.

12. GOLD Committee. Global strategy for the diagnosis, management, and prevention of chronic obstructive pulmonary disease. 2013 [updated 2013]. Available from: http://www.goldcopd.org Accessed April 1, 2014.

13. Pellegrino R, Viegi G, Brusasco V, et al. Interpretative strategies for lung function tests. Eur Respir J. 2005;26(5):948-968.

14. Vollmer WM, Gislason T, Burney P, et al. Comparison of spirometry criteria for the diagnosis of COPD: results from the BOLD study. Eur Respir J. 2009;34(3):588-597.

15. Qaseem A, Wilt TJ, Weinberger SE, et al; American College of Physicians; American College of Chest Physicians; American Thoracic Society; European Respiratory Society. Diagnosis and management of stable chronic obstructive pulmonary disease: a clinical practice guideline update from the American College of Physicians, American College of Chest Physicians, American Thoracic Society, and European Respiratory Society. Ann Intern Med. 2011;155(3):179-191.

16. Martinez FJ, Raczek AE, Seifer FD, et al; COPD-PS Clinician Working Group. Development and initial validation of a self-scored COPD Population Screener Questionnaire (COPD-PS). COPD. 2008;5(2):85-95.

17. Price DB, Tinkelman DG, Nordyke RJ, Isonaka S, Halbert RJ; COPD Questionnaire Study Group. Scoring system and clinical application of COPD diagnostic questionnaires. Chest. 2006;129(6):1531-1539.

18. Sichletidis L, Spyratos D, Papaioannou M, et al. A combination of the IPAG questionnaire and PiKo- $6^{\circledR}$ flow meter is a valuable screening tool for COPD in the primary care setting. Prim Care Respir J. 2011; 20(2):184-189, 1 p following 189.

19. Nelson SB, LaVange LM, Nie Y, et al. Questionnaires and pocket spirometers provide an alternative approach for COPD screening in the general population. Chest. 2012;142(2):358-366.

20. Tsukuya G, Matsumoto K, Fukuyama S, et al; Hisayama Pulmonary Physiology Study Group. Validation of a COPD screening questionnaire and establishment of diagnostic cut-points in a Japanese general population: the Hisayama study. Allergol Int. 2015;64(1):49-53.

21. Tsukuya G, Samukawa T, Matsumoto K, et al. Comparison of the COPD Population Screener and International Primary Care Airway Group questionnaires in a general Japanese population: the Hisayama study. Int J Chron Obstruct Pulmon Dis. 2016;11:1903-1909.
22. Kawayama T, Minakata Y, Matsunaga K, et al. Validation of symptombased COPD questionnaires in Japanese subjects. Respirology. 2008; 13(3):420-426.

23. Omori H, Kaise T, Suzuki T, Hagan G. Prevalence of airflow limitation in subjects undergoing comprehensive health examination in Japan: survey of Chronic Obstructive pulmonary disease Patients Epidemiology in Japan. Int J Chron Obstruct Pulmon Dis. 2016;11:873-880.

24. Arimura Y, Yamazaki S, Shirahama T, et al. [Accuracy of COPD questionnaires in the general health check-up setting]. Nihon Kokyuki Gakkai Zasshi. 2008;46(9):693-699. Japanese [with English abstract].

25. Landbo C, Prescott E, Lange P, Vestbo J, Almdal TP. Prognostic value of nutritional status in chronic obstructive pulmonary disease. Am J Respir Crit Care Med. 1999;160(6):1856-1861.

26. Schols AM, Slangen J, Volovics L, Wouters EF. Weight loss is a reversible factor in the prognosis of chronic obstructive pulmonary disease. Am J Respir Crit Care Med. 1998;157(6 Pt 1):1791-1797.

27. Matsumoto K, Seki N, Fukuyama S, et al; Hisayama Pulmonary Physiology Study Group. Prevalence of asthma with airflow limitation, COPD, and COPD with variable airflow limitation in older subjects in a general Japanese population: the Hisayama Study. Respir Investig. 2015;53(1):22-29.

28. Gibson PG, Simpson JL. The overlap syndrome of asthma and COPD: what are its features and how important is it? Thorax. 2009;64(8): 728-735.

29. Hardin M, Silverman EK, Barr RG, et al; COPDGene Investigators. The clinical features of the overlap between COPD and asthma. Respir Res. 2011;12:127.

30. Soler-Cataluña JJ, Cosío B, Izquierdo JL, et al. Documento de consenso sobre el fenotipo mixto EPOC-asma en la EPOC. [Consensus document on the overlap phenotype COPD-asthma in COPD]. Arch Bronconeumol. 2012;48(9):331-337. Spanish [with English abstract]. Spanish.

31. Osaka D, Shibata Y, Abe S, et al. Relationship between habit of cigarette smoking and airflow limitation in healthy Japanese individuals: the Takahata study. Intern Med. 2010;49(15):1489-1499.

32. Nishimura K, Mitsuma S, Kobayashi A, et al. COPD and diseasespecific health status in a working population. Respir Res. 2013;14:61.

33. Swanney MP, Ruppel G, Enright PL, et al. Using the lower limit of normal for the FEV1/FVC ratio reduces the misclassification of airway obstruction. Thorax. 2008;63(12):1046-1051. 


\section{Supplementary materials}

Table SI The initial draft questionnaire

\begin{tabular}{|c|c|c|}
\hline Items & Odds ratio* & $95 \% \mathrm{Cl}^{*}$ \\
\hline \multicolumn{3}{|l|}{ QI During the past year, how often did you cough? } \\
\hline Almost every day & 1.2 & $0.4-3.3$ \\
\hline $2-3$ times per week & 1.4 & $0.6-3.5$ \\
\hline Several days per month & 1.7 & $0.8-3.6$ \\
\hline Only when you had a cold or pneumonia & 1.0 & $0.5-1.9$ \\
\hline \multirow[t]{2}{*}{ Almost never } & 1.0 & Reference \\
\hline & $P$-value for trer & \\
\hline \multicolumn{3}{|c|}{ Q2 Under which of the following conditions does the coughing worsen?** } \\
\hline Change of seasons & 1.3 & $0.7-2.4$ \\
\hline During cold winters & 1.3 & $0.8-2.4$ \\
\hline When walking in the morning & 1.4 & $0.7-2.9$ \\
\hline When entering an air-conditioned room & 1.4 & $0.7-2.9$ \\
\hline When a typhoon is nearby & NA & \\
\hline In dusty environments & 1.1 & $0.6-2.0$ \\
\hline When there is volcanic ash in the air & 1.4 & $0.4-4.7$ \\
\hline On rainy days & NA & \\
\hline \multicolumn{3}{|c|}{ Q3 Does the coughing last longer than 3 weeks when you have a cold? } \\
\hline Yes & 0.7 & $0.6-1.8$ \\
\hline No & 1.0 & Reference \\
\hline \multicolumn{3}{|l|}{ Q4 During the past year, how often did you produce phlegm? } \\
\hline Almost every day & 1.7 & $0.8-3.7$ \\
\hline $2-3$ times per week & 1.7 & $0.7-4.2$ \\
\hline Several days per month & 1.0 & $0.4-2.5$ \\
\hline Only when you had a cold or pneumonia & 0.9 & $0.4-1.8$ \\
\hline \multirow[t]{2}{*}{ Almost never } & 1.0 & Reference \\
\hline & $P$-value for trer & \\
\hline \multicolumn{3}{|c|}{ Q5 Are you more likely to produce phlegm under the following conditions?** } \\
\hline When walking in the morning & 1.3 & $0.7-2.3$ \\
\hline When you have a runny nose & 1.0 & $0.5-1.8$ \\
\hline \multicolumn{3}{|c|}{ Q6 During the past year, did you have any of the following symptoms for more than 3 months?** } \\
\hline Cough only & 1.9 & $0.8-4.3$ \\
\hline Phlegm only & 1.4 & $0.7-2.9$ \\
\hline Cough and phlegm & 2.9 & $1.4-5.9$ \\
\hline \multicolumn{3}{|l|}{ Q7 On average, during the day, how much phlegm do you produce? } \\
\hline None & 1.0 & Reference \\
\hline Less than $15 \mathrm{~mL}(\mathrm{I}$ tbsp) & 1.6 & $0.9-2.8$ \\
\hline \multirow[t]{2}{*}{ More than I5 mL (I tbsp) } & 3.1 & $1.2-8.0$ \\
\hline & $P$-value for trer & \\
\hline \multicolumn{3}{|l|}{ Q8 How often do you cough up phlegm when you do not have a cold? } \\
\hline Always & 2.6 & $0.3-2.1$ \\
\hline Almost always & 2.7 & $0.9-7.7$ \\
\hline Sometimes & 2.1 & I.I-4.0 \\
\hline Rarely & 1.5 & $0.8-2.9$ \\
\hline \multirow[t]{2}{*}{ Almost never } & 1.0 & Reference \\
\hline & $P$-value for trer & \\
\hline \multicolumn{3}{|c|}{ Q9 During the past year, under which of the following conditions have you had difficulty breathing or felt out of breath?*** } \\
\hline At rest & 0.2 & $0.03-1.6$ \\
\hline When washing yourself or changing clothes & 0.8 & $0.3-2.1$ \\
\hline When walking indoors & 2.0 & $1.0-4.1$ \\
\hline When walking on a flat surface outdoors & 2.2 & $1.2-4.1$ \\
\hline During light exercise (climbing a hill or stairs) & 1.6 & $0.9-2.6$ \\
\hline During strenuous exercise (lifting heavy objects or running) & 1.4 & $0.8-2.5$ \\
\hline
\end{tabular}


Table SI (Continued)

\begin{tabular}{|c|c|c|}
\hline Items & Odds ratio* & $95 \% \mathrm{Cl}^{*}$ \\
\hline \multicolumn{3}{|c|}{ QI0 Under which of the following conditions are you more likely to be out of breath compared to people of the same age?*** } \\
\hline When walking on a flat surface outdoors & 1.8 & $0.8-4.3$ \\
\hline During light exercise (climbing a hill or stairs) & 1.9 & I.1-3.3 \\
\hline During strenuous exercise (lifting heavy objects or running) & 1.9 & I.I-3.2 \\
\hline \multicolumn{3}{|l|}{ QII How active are you in your daily life (at work and home)? } \\
\hline Very active & NA & \\
\hline Active & 1.0 & Reference \\
\hline Somewhat active & 0.9 & $0.5-1.6$ \\
\hline \multirow[t]{2}{*}{ Not active } & 0.6 & $0.2-2.2$ \\
\hline & $P$-value for tre & \\
\hline \multicolumn{3}{|c|}{ Q12 During the past year, have you ever noticed wheezing while breathing? } \\
\hline Almost every day & 9.4 & $2.7-32$ \\
\hline 2-3 times per week & NA & \\
\hline Several days per month & 7.1 & $3.2-16$ \\
\hline Only when you had a cold or pneumonia & 2.4 & $1.2-4.6$ \\
\hline \multirow[t]{2}{*}{ Almost never } & 1.0 & Reference \\
\hline & $P$-value for tre & \\
\hline \multicolumn{3}{|c|}{ Q13 During the past year, under which of the following conditions have you noticed wheezing while breathing?*** } \\
\hline When you awaken during the night & 6.2 & $3.2-12$ \\
\hline When you awaken in the morning & 5.5 & $2.7-11$ \\
\hline When walking indoors & 6.6 & $2.4-18$ \\
\hline When walking on a flat surface outdoors & 5.1 & $2.4-11$ \\
\hline During light exercise (climbing a hill or stairs) & 3.3 & $1.9-5.7$ \\
\hline During strenuous exercise (lifting heavy objects or running) & 3.2 & $1.9-5.4$ \\
\hline \multicolumn{3}{|c|}{$\begin{array}{l}\text { Q14 During the past year, which of the following problems with activities of daily living have you had due to respiratory symptoms } \\
\text { (such as cough, phlegm, or shortness of breath)?*** }\end{array}$} \\
\hline You are unable to sleep & $\mathrm{I} .0$ & $0.4-2.5$ \\
\hline You are walking slower than people of your age & 1.8 & $0.8-4.0$ \\
\hline You need to rest even when walking on flat surfaces & 4.2 & $1.6-11$ \\
\hline Light exercise is difficult (climbing a hill or stairs) & 2.6 & $1.2-5.6$ \\
\hline Strenuous exercise is difficult (lifting heavy objects or running) & 2.3 & $1.3-3.9$ \\
\hline \multicolumn{3}{|c|}{ Q15 Are your activities of daily living restricted by respiratory (lung) symptoms? } \\
\hline Yes & 2.5 & $0.5-13$ \\
\hline No & 1.0 & Reference \\
\hline \multicolumn{3}{|c|}{ Q16 During the past year, were you ever worried or panicked because you had difficulty breathing? } \\
\hline Yes & 0.8 & $0.1-6.9$ \\
\hline No & 1.0 & Reference \\
\hline
\end{tabular}

Q17 During the past year, were you ever depressed (down) because you had respiratory symptoms (such as cough, phlegm, or shortness of breath)?

$\begin{array}{lll}\text { Yes } & 2.0 & 0.8-5.2\end{array}$

No $1.0 \quad$ Reference

QI8 Has there ever been a person who smoked in the same room as you, either in your house or at your workplace, for more than I year?

Yes

1.8

I.I-3.I

No

1.0

Reference

If yes, for how long? (vs "nonpassive smoker" group)

$<10$ years

$1.4 \quad 0.5-4.2$

$10-19$ years

1.6

$0.6-4.3$

20-29 years

2.7

$30-39$ years

I.I

I.3-5.7

$>40$ years

I.6

$0.4-2.9$

$0.6-4.5$

$P$-value for trend $=0.110$

Q19 How much of the time have you lived in an environment where you were breathing exhaust gas or polluted air?

\section{Always}

NA

Sometimes

1.7

1.0

$0.9-3.2$

Almost never

Reference

Notes: NA: not available because of no subjects in both/either cases and controls. ${ }^{*}$ Odds ratios and corresponding $95 \%$ Cls were estimated models by logistic regression using age and cigarette consumption as covariates. **Odds ratios were estimated using "No" group as reference for all conditions. **** Almost none" group was used as reference, and the risk estimates for the remaining groups are shown for all conditions.

Abbreviations: $\mathrm{Cl}$, confidence interval; NA, not available. 


\section{COPDスクリーニングのための質問(COPD-Q)}

1. 現在、おいくつですか?

$\begin{array}{cccc}40 \sim 49 \text { 歳 } & 50 \sim 59 \text { 歳 } & 60 \sim 69 \text { 歳 } & 70 \text { 歳以上 } \\ \square_{0} & \square_{1} & \square_{2} & \square_{3}\end{array}$

2. かぜをひいていないのに、たんがからんでせきをすることがありますか ?

いつも ほとんどいつも ときどき まれにほとんどない

$\square_{1} \quad \square_{1} \quad \square_{1} \quad \square_{0} \quad \square_{0}$

3. 走ったり、重い荷物を運んだりしたとき、同年代の人と比べて、息切れ しやすいほうですか?

はい

いいえ

$\square_{1}$

$\square_{0}$

4. この一年間で、走ったり、重い荷物を運んだりしたとき、ゼイゼイや

ヒューヒューを感じることがありましたか?

いつも ほとんどいつも ときどき まれに ほとんどない

$\square_{2} \quad \square_{1} \quad \square_{0} \quad \square_{0} \quad \square_{0}$

5. これまで、たばこをどれくらい吸いましたか？（ )に数字を記入し、 次の計算をしてください。

1日の平均本数 $(\quad) \times$ 喫煙年数 $(\quad)=$ 合計 $($ )

合計はどれですか?

吸わない $\quad 1 \sim 399 \quad 400 \sim 999 \quad 1000$ 以上

$\square_{0} \quad \square_{1} \quad \square_{2} \quad \square_{3}$

Figure SI Japanese version of the COPD-Q.

Abbreviation: COPD-Q, COPD screening questionnaire.

International Journal of COPD

\section{Publish your work in this journal}

The International Journal of COPD is an international, peer-reviewed journal of therapeutics and pharmacology focusing on concise rapid reporting of clinical studies and reviews in COPD. Special focus is given to the pathophysiological processes underlying the disease, intervention programs, patient focused education, and self management protocols.
This journal is indexed on PubMed Central, MedLine and CAS. The manuscript management system is completely online and includes a very quick and fair peer-review system, which is all easy to use. Visit $\mathrm{http}: / / \mathrm{www}$.dovepress.com/testimonials.php to read real quotes from published authors. 